\title{
Miniscale Modelling Of Gyroscopic Effect with Application to Sheep Steering.
}

\author{
Prof.N.B.Totala ${ }^{1}$, Kanchan Rode $^{2}$, Purushottam Shelke ${ }^{3}$, MayurTope ${ }^{4}$, \\ Vaibhav Mahadik

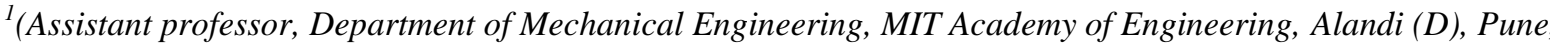 \\ Maharashtra,412105) \\ 2,3,4,5 (Department of Mechanical Engineering,MIT Academy of Engineering, Alandi(D), Pune, \\ Maharashtra,412105)
}

\begin{abstract}
A gyroscope is a device for measuring or maintaining orientation, based on the principles of momentum. Mechanically, a gyroscope is a spinning wheel or disc in which the axle is free to assume any orientation. Although this orientation does not remain fixed, it changes in response to an external torque much less and in a different direction, than it would without the large angular momentum associated with the disc's high rate of spin and inertia. Ships or sea vessels require stabilization when they face heavy sea waves. A disturbing couple acts on the ships due to sea waves, hence stabilization of ship is necessary. Due to sea waves, ship will either roll or pitch. The amplitude of rolling is much higher than amplitude of pitching. The gyroscope can be used for reducing the amplitude of rolling and hence, stabilizing the ship. The fundamental requirement of gyroscopic stabilization is that, the gyroscopic must be made to precess by some external means (example: electric motor) in such a way that the relative gyroscopic couple exerted by the rotor should oppose any disturbing couple which may act on the ship. The gyroscope used in larger marine equipment is connected to PLC. PLC generates the signal and controls the movement of the ships. This paper presents development of various ship roll motion control system together with the challenges associated with their design. It discuss the assessment of performance, the applicability of difference modals, and the control methods that have been applied in the past. This also present outlook on what are believed to be potential area of research with in this topic.
\end{abstract}

Keywords: Gyroscope, Stabilization, pitching, rolling, orientation, moment of inertia, angular momentum, spinning.

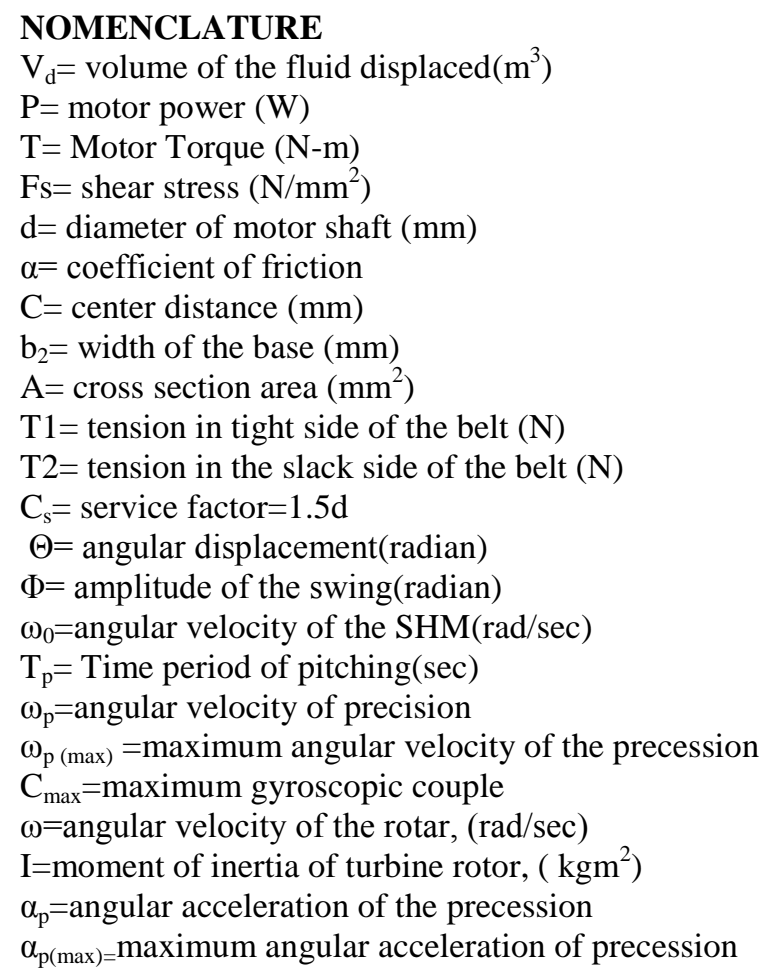




\section{Introduction}

Everything in this world is spinning. Right now, you are also spinning around on the earth at over 600 miles per hour. The earth is spinning around the sun at about 67,000 miles per hour. The entire solar system is spinning around the milky way galaxy at 5,58,000 miles per hour and this nothing compared to the unbelievable speed that the electron of every atom in the universe are spinning around their nuclei. From galactic to the atomic scale, scientists have discovered everything is spinning. A spinning body always tends to maintain the orientation of its spin axis in space, for example a bullet fired from a rifle. The external torque in suitable direction is required to change the orientation of the spin axis. Thus the basic property of the gyroscope is, it opposes the precession of the axis of spin by applying the reactive gyroscopic couple.The gyroscope is one of the most remarkable and widely recognized toys in the world, yet few people realized it and was originally developed by scientist to study spin and demonstrate that the earth is rotating, close observations of the astonishing behaviour of gyroscope led scientist to much better understanding of spin and the development of a vast number of practical applications including the gyrocompass, flight instruments, the auto pilot, gyroscopic stabilization and navigation for ships, aero planes, space stations and satellites. Ship stability is an area of naval architecture and ship design that deals with how a ship behaves at sea, both in still water waves. Stability calculations focus on the centre of gravity and the centre of buoyancy and on how these interact. In air or sea vehicles such as air planes and ships, always external disturbing couple is action on the vehicle. For the stability of such vehicles it is essential to neutralize the effect of external disturbing couple by applying equal and opposite couple. Accordingly, to generate equal and opposite reactive couple it is essential to vary the magnitude and direction of velocity of precession. [1]

The basic principle of buoyancy and floatation was discovered and stated by Archimedes over 2200 years ago. Archimedes principle may be stated as follows: A body floating or submerged in a fluid is buoyed (lifted) upward by a force equal to the weight of the fluid that would be in the volume of displaced by the fluid. This force is known as buoyant force. It follows, then that a floating body displaces its own weight of the fluid to just balance its own weight. The point through which the buoyant force acts is called the centre of buoyancy; it is located at the centre of gravity of the displaced fluid.By applying Archimedes principle, volume of irregular solids can be found by determining the apparent loss of weight when a body is wholly immersed in a liquid of known specific gravity. Specific gravities of liquids can be determined by observing the depth of floatation of a hydrometer. Further applications include problems of general floatation and of naval architectural design. [2] RuiFeng et al [3], investigated that mainstream MEMS (micro-electro-mechanical system) gyroscopes are mechanical gyroscopes that require a solid proof mass and mechanical spring structures. The large proof mass requirement limits the high-shock applications of these devices. Using gas instead of a solid resonant proof mass to detect Coriolis acceleration, MEMS thermal gyroscopes have the advantages of high-shock and strong vibration resistance. Several MEMS thermal gyroscopes have been investigated, and they can be divided into three categories: forced-convection, natural-convection, and expansion-flow. Forced-convection MEMS thermal gyroscopes require additional force, usually created by a micro pump, to create gas flow. Natural convection MEMS thermal gyroscopes use the buoyancy of a heated gas to create gas flow, and expansion-flow MEMS thermal gyroscopes use the expansion of a heated gas to create gas flow.The output of the MEMS thermal gyroscope is more vulnerable to the confounding effects of linear acceleration than that of the MEMS mechanical gyroscope.

Stephen C. Spry et al [4], considered the problem of gyroscopic stabilization of unstable vehicles in roll. He derived the full nonlinear equations of motion for the non-trivial case (not just stationary, but straight line motion, curved track, uphill track, unbalanced load, disturbance force) using Lagrangian dynamics, considering different configurations (single and double gyroscope cases), and derived linearised versions of the equations of motion. He considered stability conditions for the linear feedback controller, which yield conditions on controller gains. These conditions were verified in simulation. The stability conditions are dependent on turn rate and direction for the single gyro case, but not for the double gyro case. This is also verified by simulation.

Quan $\mathrm{Hu}$ et al [5], approached for vibration suppression of constrained space structures is proposed. Control moment gyroscopes (CMGs) are directly mounted on the structures as actuators, while angular rate sensors collocated with the CMGs are used as sensors.Collocated pairs of control moment gyroscope (CMG) and angular rate sensor are adopted as actuators/sensors. The equations of motion of a flexible structure with a set of arbitrarily distributed CMGs are developed. The detailed dynamics of the CMGs and their interactions between the flexibilities of the structure are incorporated in the formulation. Then, the equations of motion are linearized to describe the small-scale movement of the system. The optimal placement problem of the actuators/sensors on the flexible structures is solved from the perspective of the system controllability and observability.The detailed equations of motion incorporating the dynamics of the CMGs are derived by Kane's equation.

$\mathrm{Li} \mathrm{Fu}$ et al[8], a novel methodology for practical multi-position calibration procedures was designed to maximize the precision in the estimate of the deterministic error of dynamically tuned gyroscope DTG and to minimize the experiment time. The calibration accuracy of the deterministic error of DTG strongly depends on 
the multi-position calibration procedure design. Based on Euler angles transformation, a linear deterministic error model for DTG has been built up to realize the independence of model terms. For this model, a novel multi- position calibration procedure based on D-Optimal design criteria and RCGA was proposed.

\section{Methodology}

Design consists of application of scientific principles, technical information and imagination for development of new or improvised machine or mechanism to perform a specific function with maximum economy \& efficiency. [6]

Hence a careful design approach has to be adopted. The total design work has been split up into two parts

- System design

- Mechanical Design.

System design mainly concerns the various physical constraints and ergonomics, space requirements, arrangement of various components on main frame at system, man- machine interactions, No. of controls, position of controls, working environment of machine, chances of failure, safety measures to be provided, servicing aids, ease of maintenance, scope of improvement, height of machine from ground level, total weight of machine and a lot more.

In mechanical design the components are listed down and stored on the basis of their procurement, design in two categories namely,

- Designed Parts

- Parts to be purchased

For designed parts detached design is done $\&$ distinctions thus obtained are compared to next highest dimension which is readily available in market. This amplifies the assembly as well as post production servicing work. The various tolerances on the works are specified. The process charts are prepared and passed on to the manufacturing stage the parts which are to be purchased directly are selected from various catalogues \& specified so that anybody can purchase the same from the retail shop with given specifications. [6]

- MATERIAL SELECTION

Material selected for shafts is EN 24

- DESIGN CALCULATIONS

- DRIVE MOTOR (Propeller motor):

The Propeller motor or drive motor is 12 V DC motor coupled to a planetary gear box. Specifications of motor are as follows:

a) Power - 20 watt

b) Speed - $3000 \mathrm{rpm}$

c) Gear box - Planetary / epicyclic type (reduction ratio 1:3)

d) Mounting dimensions (Face mounted M12 × 1.5)[6]

Hence, Output speed - 1000RPM

To calculate Motor Torque:

$\mathrm{P}=2 \pi \mathrm{NT} / 60$

$\mathrm{T}=60 \mathrm{P} / 2 \pi \mathrm{N}$

$\mathrm{T}=0.064 \mathrm{~N}-\mathrm{m}$

Gear Box Reduction Ratio $=1: 3$

$\mathrm{T}$ design $=3 \times \mathrm{T}=0.192 \mathrm{~N}-\mathrm{m}$

- DESIGN OF PROPELLER MOTOR SHAFT:

MATERIAL SELECTION: Ref:- PSG (1.10 \& 1.12) + (1.17)[7]

\begin{tabular}{|l|l|}
\hline $\begin{array}{l}\text { ULTIMATE TENSILE } \\
\text { STRENGTH N/mm }\end{array}$ & $\begin{array}{l}\text { YIELD STRENGTH } \\
\mathrm{N} / \mathrm{mm}^{2}\end{array}$ \\
\hline 800 & 680 \\
\hline
\end{tabular}

Material Properties For Propeller Motor Shaft

\section{ASME CODE FOR DESIGN OF SHAFT:}

Since the loads on most shafts in connected machinery are not constant, it is necessary to make proper allowance for the harmful effects of load fluctuations

According to ASME code permissible values of shear stress may be calculated from various relations.[6]

fs $\max =0.18 \times 800$

$=144 \mathrm{~N} / \mathrm{mm}^{2}$

OR 
fs $\max =0.3 \mathrm{fyt}$

$=0.3 \times 680$

$=204 \mathrm{~N} / \mathrm{mm}^{2}$

Considering minimum of the above values fs $\max =144 \mathrm{~N} / \mathrm{mm}^{2}$

Shaft is provided with tapped clamping hole, this will reduce its strength. Hence reducing above value of allowable stress by $25 \%$,

$\mathbf{f}_{\mathrm{s}} \max =108 \mathrm{~N} / \mathrm{mm}^{2}$

This is the allowable value of shear stress that can be induced in the shaft material for safe operation.

$\mathrm{T}$ design $=0.192 \mathrm{~N}-\mathrm{m}$

\section{- DESIGN OF OPEN BELT DRIVE}

\section{OPEN BELT DRIVE FOR PROPELLER SHAFT}

Power is transmitted from the motor shaft to the Propeller shaft of drive by means of an open belt drive.[6]

Motor pulley diameter $=12 \mathrm{~mm}$

IP shaft pulley diameter $=24 \mathrm{~mm}$

Reduction ratio $=2$

Propeller shaft speed $=1000 / 5$

$=500 \mathrm{rpm}$

Torque at IP shaft $=0.192 / 2$

$$
=0.096 \mathrm{~N}-\mathrm{m}
$$

\section{DESIGN OF OPEN BELT DRIVE}

Coefficient of friction $=0.23$

Maximum allowable tension in belt $=200 \mathrm{~N}$

Centre distance $=120$

$\alpha=180-\sin -1(\mathrm{D}-\mathrm{d}) / 2 \mathrm{C}$

$\alpha=180-\sin -1(24-12) / 2 \times 120$

$\alpha=1790 \alpha=3.12^{\circ}$

Now,

$$
\mathrm{e} \alpha \mu / \sin (\theta / 2)=\mathrm{e} 0.23 \times 3.12 \sin (40 / 2)=419
$$

Width (b2) at the base is given by

b2 $=6-2(4 \tan 20)=3.1$

Area of cross section of belt $=1 / 2\{6+3.1\} \times 4$

$\mathrm{A}=18.2 \mathrm{~mm}^{2}$

Now mass of belt $/ \mathrm{m}$ length $=0.23 \mathrm{~kg} / \mathrm{m}$

$\mathrm{Tc}=\mathrm{m} \mathrm{V} 2$

$=4.034 \mathrm{~N}$

$\mathrm{T} 1=\mathrm{Tmax}-\mathrm{Tc}$

$=195.966$

$=196 \mathrm{~N}$

$\mathrm{T} 1 / \mathrm{T} 2=\mathrm{e} \mu \alpha / \sin (\theta / 2)$

$=4$

$\mathrm{T} 2=49 \mathrm{~N}$

Result:

Tension in tight side of belt $(\mathrm{T} 1)=196 \mathrm{~N}$

Tension in slack side of belt $(\mathrm{T} 2)=49 \mathrm{~N}$

- DESIGN OF PROPELLER SHAFT:

MATERIAL SELECTION: Ref:- PSG (1.10 \& 1.12) + (1.17)

\begin{tabular}{|l|l|}
\hline $\begin{array}{l}\text { ULTIMATE TENSILE } \\
\text { STRENGTH } \\
\mathrm{N} / \mathrm{mm}^{2}\end{array}$ & YIELD STRENGTH \\
\hline 400 & $\mathrm{~N} / \mathrm{mm}^{2}$ \\
\hline
\end{tabular}

Table 4.2 Material Properties For Propeller Shaft

ASME CODE FOR DESIGN OF SHAFT: 
Since the loads on most shafts in connected machinery are not constant, it is necessary to make proper allowance for the harmful effects of load fluctuations

According to ASME code permissible values of shear stress may be calculated from various relation.[6]

fs $\max =0.18 \times 400$

$=72 \mathrm{~N} / \mathrm{mm}^{2}$

OR

fs $\max =0.3 \mathrm{fyt}$

$=0.3 \times 280$

$=84 \mathrm{~N} / \mathrm{mm}^{2}$

Considering minimum of the above values,

fs $\max =72 \mathrm{~N} / \mathrm{mm}^{2}$

Shaft is provided with tapped clamping hole; this will reduce its strength. Hence reducing above value of allowable stress by $25 \%$

fs $\max =54 \mathrm{~N} / \mathrm{mm}^{2}$

This is the allowable value of shear stress that can be induced in the shaft material for safe operation.

$\mathrm{T}$ design $=0.192 \mathrm{~N}-\mathrm{m}$

\section{- STEERING MOTOR:}

The Steering motor or drive motor is 12 VDC motor coupled to an planetary gear box. Specifications of motor are as follows:[6]

a )Power : 5 watt

b) Speed $=300 \mathrm{rpm}$

c)Gear box : Planetary /epicyclic type (reduction ratio : 1:5)

d) Mounting dimensions (Face mounted M12 x 1.5)

Hence, Output speed - 60RPM[6]

$\mathrm{P}=2 \pi \mathrm{NT} / 60$

To calculate Motor Torque:

$\mathrm{T}=60 \mathrm{P} / 2 \pi \mathrm{N}$

$\mathrm{T}=0.318 \mathrm{~N}-\mathrm{m}$

Gear Box Reduction Ratio $=1: 5$

$\mathrm{T}$ design $=3 \times \mathrm{T}=0.5 \mathrm{~N}-\mathrm{m}$

.DESIGN OF STEERING MOTOR SHAFT:

MATERIAL SELECTION: Ref :- PSG $(1.10 \& 1.12)+(1.17)$ [7]

\begin{tabular}{|l|l|l|}
\hline DESIGNATION & $\begin{array}{l}\text { ULTIMATE TENSILE } \\
\text { STRENGTH } \\
\text { N/mm2 }\end{array}$ & YEILD STRENGTH N/mm2 \\
\hline EN 24 & 800 & 680 \\
\hline
\end{tabular}

Material Properties For Steering Motor Shaft

\section{ASME CODE FOR DESIGN OF SHAFT:}

Since the loads on most shafts in connected machinery are not constant, it is necessary to make proper allowance for the harmful effects of load fluctuations.

According to ASME code permissible values of shear stress may be calculated from various relation:[6]

fs $\max =0.18 \times 800$

$=144 \mathrm{~N} / \mathrm{mm}^{2}$

OR

fs $\max =0.3 \mathrm{fyt}$

$=0.3 \times 680$

$=204 \mathrm{~N} / \mathrm{mm}^{2}$

Considering minimum of the above values fs $\max =144 \mathrm{~N} / \mathrm{mm}^{2}$

Shaft is provided with tapped clamping hole, this will reduce its strength.

Hence reducing above value of allowable stress by $25 \%$, 
fs $\max =108 \mathrm{~N} / \mathrm{mm}^{2}$

This is the allowable value of shear stress that can be induced in the shaft material for safe operation.

$\mathrm{T}$ design $=0.192 \mathrm{~N}-\mathrm{m}$

- DESIGN OF RACK AND PINION FOR STEERING INPUT DATA:

1. Rack: 1 module, 40 teeth

2. Pinion: 1 module, 15 teeth

3. Tdesign $=1500 \mathrm{~N}-\mathrm{mm}$

Material of pinion and gear is High grade industrial polyamide

Trade Name: Nylon66

Tensile strength $=82 \mathrm{~N} / \mathrm{mm}^{2}$

Sult pinion $=$ Sult rack $=82 \mathrm{~N} / \mathrm{mm}^{2}$

Service factor $(\mathrm{Cs})=1.5 \mathrm{dp}=12$

Now;

$\mathrm{T}=\mathrm{Pt} \mathrm{x} d \mathrm{p}$

$\mathrm{Pt}=200 \mathrm{~N}$

$\mathrm{Wt}=$ Sbym

Lewis Strength equation

Where ;

$\mathrm{Y}=0.484-(2.86 / \mathrm{Z})$

$\mathrm{Y}=0.484-(2.86 / 15)$

$\mathrm{Yp}=0.293$

Syp $=24$

WT $=($ Syp $) \times \mathrm{b} \times \mathrm{m}$

$=24 \times 10 \mathrm{~m} \times \mathrm{m}$

$\mathrm{WT}=240 \mathrm{~m} 2$

Equation (A) \& (B)

$240 \mathrm{~m} 2=200$

$\mathrm{m}=0.912$

Selecting standard module $=1 \mathrm{~mm}$

GEAR DATA:

No. of teeth on pinion $=15$

No. of teeth on rack $=40$

Module $=1 \mathrm{~mm}$

\section{- GYROSCOPE MOTOR:}

The Propeller motor or drive motor is 12 V DC motor coupled to an planetary gear box. Specifications of motor are as follows:[6]

a) Power- 10watt

b) Speed - $6000 \mathrm{rpm}$

c) Gear box - Planetary /epicyclic type (reduction ratio : 1:3)

d) Mounting dimensions (Face mounted M12 $\times 1.5$ )

Hence, Output speed - 2000 RPM

To calculate Motor Torque:

$$
\mathrm{T}=0.047 \mathrm{~N}-\mathrm{m}
$$

Gear Box Reduction Ratio $=1: 3$

$\mathrm{T}$ design $=3 \times \mathrm{T}=0.143 \mathrm{~N}-\mathrm{m}$

.DESIGN OF GYROSCOPE MOTOR SHAFT:

MATERIAL SELECTION: Ref:- PSG (1.10 \& 1.12) + (1.17)[7]

\begin{tabular}{|l|l|l|}
\hline DESIGNATION & $\begin{array}{l}\text { ULTIMATE TENSILE } \\
\text { STRENGTH } \\
\mathrm{N} / \mathrm{mm} 2\end{array}$ & $\begin{array}{l}\text { YEILD STRENGTH } \\
\mathrm{N} / \mathrm{mm} 2\end{array}$ \\
\hline EN 24 & 800 & 680 \\
\hline
\end{tabular}

Material Properties For Gyroscope Motor Shaft 
ASME CODE FOR DESIGN OF SHAFT:

Since the loads on most shafts in connected machinery are not constant, it is necessary to make proper allowance for the harmful effects of load fluctuations

According to ASME code permissible values of shear stress may be calculated from various relations.[6]

fs $\max =0.18 \times 800$

$=144 \mathrm{~N} / \mathrm{mm}^{2}$

OR

fs $\max =0.3 \mathrm{fyt}$

$=0.3 \times 680$

$$
=204 \mathrm{~N} / \mathrm{mm}^{2}
$$

Considering minimum of the above values fs $\max =144 \mathrm{~N} / \mathrm{mm}^{2}$

Shaft is provided with tapped clamping hole, this will reduce its strength. Hence reducing above value of allowable stress by $25 \%$,

fs $\max =108 \mathrm{~N} / \mathrm{mm}^{2}$

This is the allowable value of shear stress that can be induced in the shaft material for safe operation.

$\mathrm{T}$ design $=0.192 \mathrm{~N}-\mathrm{m}$

\section{- FINAL DESIGN:}

\section{Construction And Working}

The final design that was chosen for this project was catamaran hull surface vessel with motor as the propulsion system. The catamaran hull contain of four water tight hulls that are connected by an above structure.

\section{- Hull and Platform:}

The hulls of the vessel will be constructed from aluminium pipe. Rankine oval shaped caps will seal the ends of the pipes. A frame constructed of aluminium angle iron beams will connect the two hulls. In transverse direction, two angle iron beams will connect the hulls the transverse lengths of the angles iron will be determined from the scale model testing results.

The frame structure will be completed by two longitudinal angle beams. To connect the frame to the hull, threaded rod will be shaped around the aluminium pipe. Its purpose is to raise the platform to a height of 1 foot above the water. The spacer material is yet to be determined.

The platform material and dimensions are yet to be determined. The platform is independent of the size of the payload to determine its size and strength. The platform will be attached to all the four angle iron beams by bolts. The frame construction requires cutting and welding of aluminium angle. Holes will also be drilled in angle for the threaded rods. This will be done in shop by a technician.

\section{- $\quad$ Steering and Propulsion:}

The power of the vessel will come from battery for deep cycle usage. The propulsion and steering will come from an electric DC outboard motor. The motor that was chosen for this project is a riptide transom model, which is designed for use in salt water and can deliver a maximum thrust of $45 \mathrm{lbs}$. The motor will be directly attached to the aluminium angle frame by means of supplied clamp.

The vessel will be controlled using a remote control system. The controller will allow control of 2 channels with the required voltage range for necessary controls. The control system will be responsible to control the speed and direction of the mounted outboard motor.

\section{- Direction Control:}

The direction of the outboard motor will be controlled using the remote control receiver. The receiver will control the linear actuator that will drive the torque arm to turn the motor. This torque arm will be linked to the shaft of the outboard. Since the outboard is free to pivot in the motor mount the resistance to turning will be only due to the propeller in water 


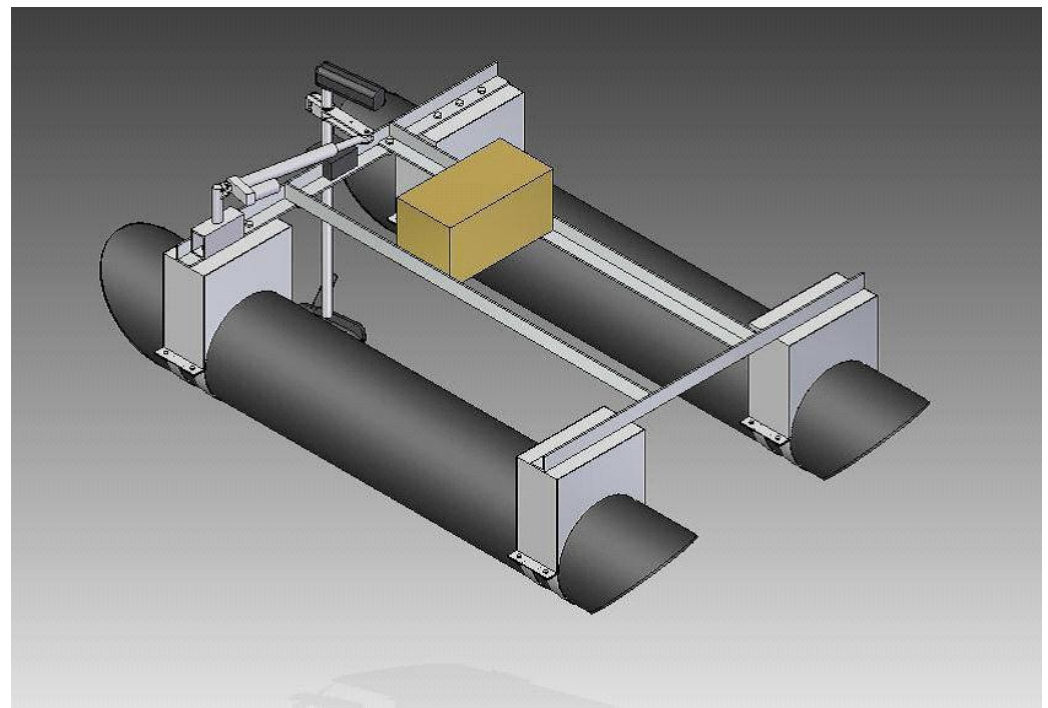

Fig 1:-Catamaran hull

\section{.WORKING}

.GYROSCOPIC EFFECT ON SHIPS DURING STEERING:

Steering of a ship is the turning of a complete ship in a curve towards the left or right. The rotor and the propeller of the ship is spinning about its own axis hence steering of the ship leads to the precession of the spin axis. Due to this, the reactive gyroscopic couple is applied by the rotor shaft on the ship. The direction of reactive gyroscopic couple is determined by considering following four cases:[1]

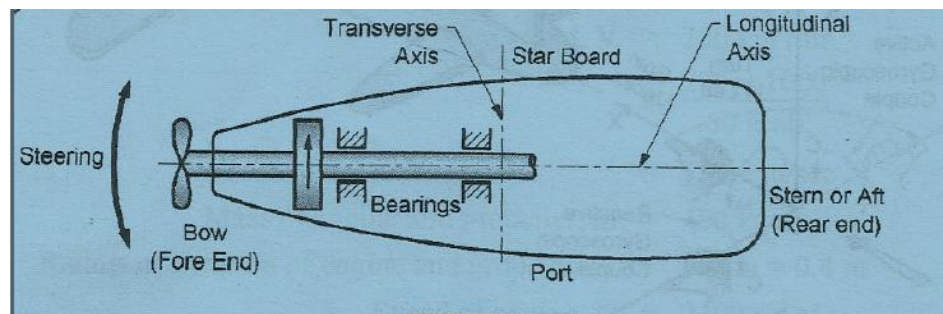

Fig 2:-Steering of ship

\begin{tabular}{|l|l|}
\hline Condition & Effect of reactive gyroscopic couple \\
\hline $\begin{array}{l}\text { CASE 1: When rotor rotates in anticlockwise } \\
\text { direction and ship pitches upward. }\end{array}$ & to turn the ship towards starboard side or right side \\
\hline $\begin{array}{l}\text { CASE 2: When rotor rotates in anticlockwise } \\
\text { direction and ship pitches downward. }\end{array}$ & to raise the bow or fore end and dip the stern or rear end. \\
\hline $\begin{array}{l}\text { CASE 3: When rotor rotates in clockwise direction } \\
\text { and ship pitches upward. }\end{array}$ & To raise the bow or fore end and dip the stern or rear end. \\
\hline $\begin{array}{l}\text { CASE 4: When rotor rotates in clockwise direction } \\
\text { and ship pitches downward }\end{array}$ & to raise the stern or rear end and dip the bow or fore end. \\
\hline
\end{tabular}

\section{- GYROSCOPIC EFFECT ON SHIPS DURING PITCHING:}

Pitching of ship is the cyclic up and down motion of bow and stern in a vertical plane about transverse axis as shown in figure. Rotor is spinning about its own axis. Hence, the pitching of the ship about the transverse axis is nothing but the precession of the spin axis. The transverse axis of the ship is the axis of precession. Due to this the reactive gyroscopic couple is applied by the rotor shaft on the ship. The pitching of the ship is assumed to take place with simple harmonic motion.[1] 


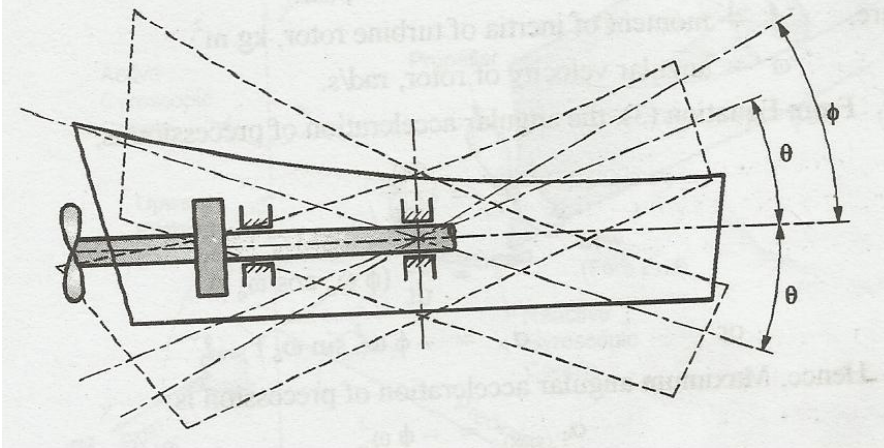

fig 3:-Pitching of Ship

\begin{tabular}{|l|l|}
\hline Condition & Effect of reactive gyroscopic couple \\
\hline $\begin{array}{l}\text { CASE 1: When rotor rotates in anticlockwise } \\
\text { direction and ship pitches upward. }\end{array}$ & to turn the ship towards starboard side or right side \\
\hline $\begin{array}{l}\text { CASE 2: When rotor rotates in anticlockwise } \\
\text { direction and ship pitches downward. }\end{array}$ & to turn the ship towards port side or left side \\
\hline $\begin{array}{l}\text { CASE 3: When rotor rotates in clockwise } \\
\text { direction and ship pitches upward. }\end{array}$ & to turn the ship towards port side or left side \\
\hline $\begin{array}{l}\text { CASE 4: When rotor rotates in clockwise } \\
\text { direction and ship pitches downward }\end{array}$ & to turn the ship towards starboard side or right side \\
\hline
\end{tabular}

- GYROSCOPIC EFFECT ON SHIPS DURING ROLLING:

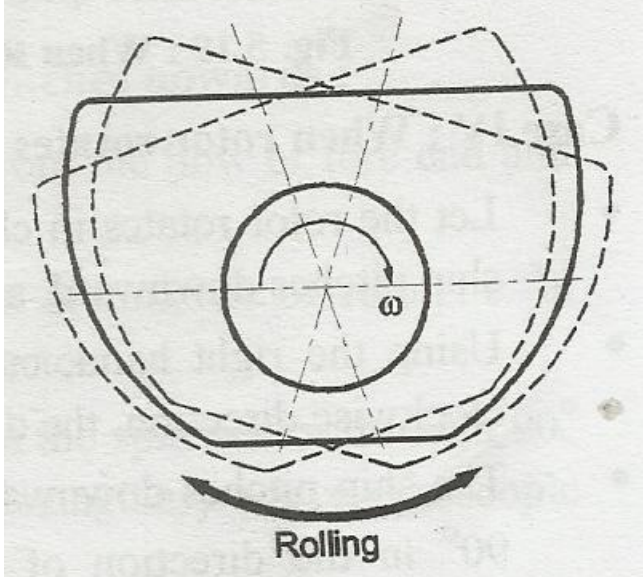

fig 4.Rolling of Ship

Rolling of ship is the side wise oscillating motion of ship about longitudinal axis that is in rolling motion, port and star board side goes up and down alternately as shown in figure. In case of rolling action the axis of rotor and axis of rolling of ship are same. Hence there is no precession of the axis of rotor or axis of spin and hence, there in no gyroscopic effect during rolling of the ship.[1]

\section{Testing And Result}

The model was tested in the SWIMMING POOL of MAHALAXMI VIHAR in still water as well as in INDRAYANI RIVER, ALANDI in waving water.

The model has a layer of pads (foam) below the hulls to for increasing the surface area of the model. The model was floating in water with the bow end a bit more submerged in water due to the weight of the gyroscope. The results were satisfactory. There was no problem in propulsion and steering of the model. But the gyroscope is not very sensitive to the unbalanced force. 


\section{- APPLICATION:}

\section{Application And Future Scope}

-It is used in Military and security vehicles.

- It is used in Civilian and research vehicles.

- It is used in Marine equipment.

- C-CAT: The system is designed for use in water quality sampling, environmental assessments and hydrography.

- C-STAT: It offers a new capability in the positioning of equipment at sea for extended durations without the need for ships or sea-bed anchoring.

\section{- FUTURE SCOPE:}

- It may be used as AUSV.

- Use Sensor Fusion

- Advanced GPS system, along with on-board intelligence

- US Navy research and development .

\section{Conclusion}

We consider the problem of gyropscopic stabilization of unstable vehicles in steering,pitching and rollingl.After testing we came to conclusion that the gyroscope used in the model is a RATE GYROSCOPE. It shows the movement in the direction of the unbalanced force indicating that extra mass should be added on the opposite side of the indicated direction. MEMS thermal gyroscopes are better suited for high-shockapplications than MEMS mechanical gyroscopes. Future work includes further analysis of the equations of motion, and comparisons to other gyroscopic systems such as ship stabilizers. In addition, we will also further analyze control properties, compare the performance of the early mechanical feedback systems to more modern approaches, perform simulations for a full scale vehicle, and analyze results from the scaled model experiments.

\section{References}

[1] Theory of Machines"- Compiled By- Khurmi R.S, Gupta J.K, Published By- Eurasia Publishing House (Pvt) Ltd, New Delhi .

[2] Schaum ${ }^{\text {ee }}$ Outline Of Fluid Mechanics And Hydraulics, Third Edition.

[3] RuiFeng et al, MEMS thermal gyroscope with self-compensation of the linearacceleration effect

[4] Stephen C. Spry et al, Gyroscopic Stabilization of Unstable Vehicles: Configurations, Dynamics, and Control.

[5] Quan Hu et al, Dynamics and Vibration Suppression of Space Structures with Control Moment Gyroscopes

[6] Design of Machine Elements" Compiled By -V.B.Bhandari Published By: McGraw-Hill Education India vt.Ltd. Third Edition.

[7]. Design Data Book For Engineers" Compiled By-Faculty of Mechanical Engineering, PSG College of Technology, Coimbatore, Published By: KalaikathirAchchagam. Revised Edition- 1978.

[8] Li Fu et al,.A novel calibration procedure for dynamically tuned gyroscope designed by D-optimal approach. 